\title{
STUDI LITERATUR: ACUPRESSURE PERICARDIUM DAN AROMATHERAPY CITRUS UNTUK MENGURANGI MUAL MUNTAH IBU HAMIL
}

\author{
Uning Sulistiarini ${ }^{1)}$ Melyana Nurul $\mathrm{W}^{2)}$ Dyah Lustika Rahayu ${ }^{3)}$ \\ E-mail address : uningsulistiarini@gmail.com
}

\begin{abstract}
Changes during pregnancy that make discomfort require an adaptation process. Nausea and vomiting discomfort can occur in $60-80 \%$ of primigravida pregnancies and $40-60 \%$ of multigravida pregnancies. Symptoms of nausea can be severe if not managed properly. Various efforts have been made to reduce maternal nausea and vomiting. In addition to pharmacological therapy can also be carried out nonphamacological therapy that is simple, inexpensive, effective, and without adverse side effects, namely in the form of acupressure or massage at the point 6 of the pericardium and administration of aromatherapy.

The aim of the study was to measure literature related to pericardium acupressure and citrus aromatherapy. Methods: the method used is a literature study on the effectiveness of pericardium acupressure and citrus aromatherapy for pregnancy. The source of literature uses electronic media with various journals and libraries in 2008-2018 from several databases, namely Sience Direct and Google Scholar.The article found as many as 5 journals consisting of 2 international journals and 3 national journals. Research design: descriptive design, by analyzing journals related to the topic. Results: the results of the literature review were complementary follow-up treatment of pericardium P6 acupressure and citrus aromatherapy categorized as safe and effective enough to reduce nausea and vomiting in pregnancy. The conclusions from this literature review that the of pericardium P6 acupressure and citrus aromatherapy administration showed its effectiveness in combining nausea and vomiting in pregnancy.
\end{abstract}

Keywords: vomiting; nausea; pregnancy ; accupressure; aromatherapy

${ }^{1)}$ Students Of Masters Study Program,Poltekkes Kemenkes Semarang.

${ }^{2)}$ Lecturer of Poltekkes Kemenkes Semarang

${ }^{3)}$ Midwife of Puskesmas Rawalo, Kabupaten Banyumas

\section{Pendahuluan}

Dalam indikator suatu bangsa salah satunya adalah dapat melakukan pembangunan berkelanjutan dengan melaksanakan Pembangunan Kesehatan(Kemenkes, 2017).Salah satu tujuanSustainable Development Goals 2030 (SDGs) dengan menjamin kehidupan yang sehat dan mendorong kesejateraan bagi semua masyarakat di Indonesia, dalam pencapaian tujuan tersebut dilakukan upaya untuk memberikan perhatian khusus pada penyelenggaraan Pelayanan Kesehatan Ibu dan Anak (KIA)(Ermalena, 2017).

Kehamilan yang dialami wanita merupakan suatu proses normal dan alami. Selama hamil seorang ibu 
mengalami perubahan-perubahan yang terjadi baik fisiologis maupun psikologis. Perubahan fisiologis diantaranya perubahan organ reproduksi, sistem kardiovaskuler, pernafasan, ginjal, integumen, mukuloskeletal, neurologi, pencernaan, dan endokrin.Perubahanperubahanyang akan terjadi tersebut dapatmenyebabkan ibu hamil mengalami

ketidaknyamanan(Prawirohardjo,

2010). Ketidaknyamanan yang dirasakan oleh setiap ibu hamil berbeda-beda pada tiap trimester kehamilan. Salah satu keluhan yang sering dirasakan dalam periode kehamilan adalah mual muntah atau bisa disebut juga dengan morning sickness.Rangsangan yang terjadinya morning sickness yaitu perubahan dalam metabolisme karbohidrat dan lipid menyebabkan hipoglikemia terutama pada saat bangun tidur(Madjunkova et al., 2013).

$$
\text { Wanita hamil (50-90\%) }
$$

mengalami mual dan muntah selama trimester pertama, $28 \%$ mengalami mual saja, sedangkan $52 \%$ mual dan muntah. Gejala itu muncul biasanya pada minggu ke-4 dan menghilang pada minggu ke-16 serta juga mencapai puncak antara minggu ke- 8 dan minggu ke-12. Sekitar 53\% dari terjadinya muntahitu antara pukul 06.00 dan 12.00. Diantaranya 20-30\% dari wanita hamil juga dapat mengalami gejala mual dan muntah pada usia kehamilan di atas 20 minggu sampai dengan waktu akan melahirkan(Madjunkova et al., 2013). Mual muntah termasuk gejala alami yang bisa dirasakan oleh ibu hamil terutama pada ibu hamil trimester I, dimana yang biasanya ibu hamil akan merasakan pusing, sensasi air liur yang berlebihan,danmengeluarkan sebagian atau semua makanan yang sudah dikonsumsi. Adapun pada kasus ibu hamil yang mengalami mual muntahberlebih dan bertambah parah apalagi sampai mengganggu keadaan umum juga mengganggu pekerjaan ibu hamil sehari-hari bisa dikatakan dengan ibu hamil dengan hiperemesis gravidarum. Mual muntah kehamilan dapat berdampak serius bagi ibu dan janin. Dampak tersering yang merugikan janin akibat muntah yang parah adalah kelahiran prematur dan berat badan lahir rendah (BBLR). Studi prospektif yang dilakukan McCarthy dkk, 2011,menunjukkan dari 4,8\% ibu hamil dengan mual muntah itu menderita hiperemesis gravidarum, dimana $2,1 \%$ membutuhkan rawat inap dan $9 \%$ bisa berkembang menjadi pre-eklampsi serta dapat berisiko mengalami kelahiran prematur spontan $(\mathrm{OR}=2,6 ; 95 \%$ CI 1.2-5.7(McCarthy et al., 2011).Dan dalam penelitian Madjunkova dkk, menunjukkan bahwa 95\% ibu hamil yang mengalami mual muntah sedang sampai berat, $13 \%$ bisa berkembang menjadi hiperemesis gravidarum(Madjunkova et al., 2013).

Dalam ilmu kesehatan, pengobatan untuk mengurangi mual 
muntah pada ibu hamil dapat dilakukan dengancara terapi secara farmakologi dan non farmakologi. Terapi farmakologi dilakukan dengan pemberian antihistamin, antimietik, dan kortikosteroid. Terapi non farmakologi dilakukan dengan cara pengaturan diet, dukungan emosional, serta bisa juga menggunakan akupresur dan jahe(Runiari, 2010). Adapun penggunaan terapi komplementer dan alternatif atau Complementary and Alternative Medicine (CAM) yang semakin populer pada masyarakat umum dan tenaga kesehatan profesional, dengan insiden antara 30\% dan 50\%(Danise, 2009).Salah satu carayang gampang diterapkan dalam masyarakatdiantaranya dengan teknik acupressure pericardium. Proses teknik akupresur menitik beratkan pada titik-titik saraf tubuh(Fengge, 2012). Akupresur adalah merupakan teknik pengobatan komplementer yang berkaitan dengan akupunktur yaitu dengan melakukan tekanan pada titiktitik tertentu pada tubuh. Di dalam pengobatan Tiongkok, titik perikardium 6 dianggap kunci dalam mengurangi gejala mual muntah. Gejala pada mual muntah tersebut dapat dikurangi dengan tekanan langsung atau memakai gelang tangan (Wrist Band)pada 3 jari di bawah pergelangan tangan(Ebrahimi et al., 2010). Adapun cara lain yang dapat dilakukan selain teknik acupressure pericardiumyaitubisa dengan pemberian aromaterapi. Aromaterapi merupakan teknik penggunaan minyak esensial dari tumbuhan yang digunakan secara intensif pada pencegahan atau mengobati penyakit, mengurangi stres, atau meningkatkan status kesehatan baik fisik maupun psikologis(Tillett and Ames, 2010).Minyak aromaterapijuga banyak disarankan oleh praktisi folkloric yang juga bermanfaat pada penyakit Alzheimer, kanker, kardiovaskular, kehamilan, nyeri persalinan, dll(Jimbo et al., 2009).Salah satu penelitian mengungkapkan bahwa efek pijat, pijat aromaterapi, dan aromaterapi dianjurkan untuk pelayanan ibu hamil begitu juga pelayanan ibu postpartum. Dalam penelitian yang dilakukan memberikan efek produksi ASI yang meningkat setelah dilakukan perlakun. Cara ini juga menjadi solusi alternatif untuk memecahkan masalah, terutama bagi wanita yang mengalami keluhan atau kecemasan dalam proses kehamilan maupun postpartum (Agustina et al., 2016). Namun dalam pemilihan pemberian aromaterapi juga harus diperhatikan, karena ada beberapa aromaterapi yang memiliki kontra indikasi pada keluhan yang dirasakan.

Menurut penelitian(Damarasri, 2017), minyak esensial (Citruslemon) adalah salah satu minyak herbal yang paling banyak digunakan pada kehamilan dan dianggap sebagai obat yang aman pada kehamilan. Menurut salah satu studi dalam penelitian ini, $40 \%$ wanita telah menggunakan aroma lemon untuk meredakan mual dan muntah, dan $26,5 \%$ dari mereka telah 
mengakui aromaterapi citrus adalah cara yang efektif untuk mengontrol gejala mual muntah.

Berdarkan uraian di atas penulis tertarik melakukan penelitian tentang efektifitas penerapan acupressure pericardium dan aromatherapy citrus untuk mengurangi mual muntah pada ibu hamil di Desa Rawalo Wilayah Kerja Puskesmas Rawalo Kabupaten Banyumas.

\section{Metode Penelitian}

Metode yang digunakan dalam studi ini adalah metadata analisis dengan menggunakan tinjauan literature (literature view) dengan mencari artikel yang relevan dengan topic akupresur perikardium dan aromaterapi citrus untuk mual muntah ibu hamil. Sumber tinjauan menggunakan media elektronik dari beberapa database antara lain Sience Direct dan Google Shcolar yang dipublishkan kurun waktu tahun 2008 sampai tahun 2018. Artikel yang ditemukan dan memenuhi kriteria sebanyak 5 jurnal yang terdiri dari 2 Jurnal Internasional dan 3 Jurnal Nasional. Keyword yang digunakan penulis adalah vomiting/ muntah; nausea/ mual; pregnancy/ ibu hamil; acupressure/ akupresur; aromatherapy/ aromaterapi. Artikel yang diperoleh, direview untuk memilih kriteria yang sesuai dengan kriteria inklusi, disusun secara sistematis, dibandingkan dengan satu sama lain dan dibahas dengan literatur yang lain yang terkait.

\section{Hasil dan Pembahasan}

Pencarian jurnal yang dilakukan pada data base dengan menggunakan kata kunci: mual muntah, ibu hamil, akupresur, aromaterapi. Artikel yang ditemukan dan memenuhi kriteria sebanyak 5 jurnal yang terdiri dari 2 jurnal internasional dan 3 jurnal nasional.

Menurut penelitian di Iran yang diteliti oleh (Saberi et al., 2013),berjudul "Acupressure and ginger to relieve nausea and vomiting in pregnancy: a randomized study",dengan jumlah responden sebanyak 159 ibu hamil. Penelitian ini memiliki kriteria inklusi diantaranya bersedia untuk berpartisipasi dalam penelitian, memiliki keluhan mual muntah dari ringan sampai sedang, usia kehamilan kurang dari 16 minggu, dengan kehamilan tunggal, responden dapat membaca dan menulis, tidak memiliki riwayat lain penyakit seperti gangguan pencernaan, tidak sedang menggunakan metode lain untuk pengobatan NVP (Nausea Vomiting Pregnancy) dalam 3 minggu terakhir, dan bisa makan kapsul jahe atau dapat menggunakan gelang seperti yang ditentukan dalam penempatan yang benar. Dibagi menjadi 2 kelompok, yaitu kelompok perlakuan dan kelompok kontrol. Kelompok perlakuan sebanyak 53 ibu hamil yang diberikan gelang Sea Band elastis dengan kancing yangmenekan pada titik P6 dipakai terus menerus kecuali ketika ibu mandi. Intervensi yang 
diberikan selama 7 hari, 3 hari awal yang tidak diberi intervensi, 4 hari berikutnya menggunakan gelang akupresur sea band. Kelompok kontrol sebanyak 53 ibu hamil yang tidak diberikan intervensi, dan $53 \mathrm{ibu}$ hamil sebagai kelompok placebo diberikan 12 kapsul jahe $250 \mathrm{mg}$ bernama Zintoma untuk 4 hari (hari ke 4-7) dan setiap hari 3 kapsul. Penelitian ini menunjukan jahe lebih efektif daripada akupresur untuk meringankan gejala mual dan muntah ringan sampai sedang pada ibu hamil.

Menurut penelitian dari (Fitriana, 2017). yang berjudul "Perbandingan efektifitas akupresure perikardium dengan aromaterapi terhadap penurunan mual muntah pada Ibu hamil di Pulau Lombok", dengan sampel sebanyak $60 \mathrm{ibu}$ hamil trimester I hiperemesis gravidarum yang memenuhi kriteria inklusi pada wilayah Labulia, Lombok Tengah dan di wilayah Labuhan Lombok, Lombok Timur. Tujuan dari penelitian ini adalah untuk mengetahui perbandingan efektifitas akupresur perikardium dengan aromaterapi terhadap penurunan mual muntah pada Ibu hamil di Pulau Lombok. Rancangan penelitian menggunakan pre eksperimental dengan menggunakan two group post test design. Hasil penelitian ini menunjukkan bahwa pada pemberian aromaterapi jeruk lebih efektif untuk menurunkan mual muntah dari pada akupresure perikardium dengan nilai Signifikan $<\alpha$ $(0,000<0,05)$ dan ibu hamil dengan tingkat mual muntah berat paling sedikit. Hasil dari penelitian ini sama halnya dengan penelitian yang dilakukan oleh penulis di Desa Rawalo Kabupaten Banyumas pada Bulan Juli 2018 yang menunjukkan keefektifan pengurangan mual muntah pada ibu hamil setelah dilakukan akupresur perikardium dan pemberian aromaterapi citrus pada ketiga responden.

Menurut penelitian dari(Nur et al., 2014), yang berjudul "Pengaruh Akupresur Perikardium 6 Terhadap Mual Muntah Kehamilan Kurang 16 Minggu", dengan jumlah sampel sebanyak 33 yang terdiri dari 17 kelompok intervensi dan kelompok kontrol. Adapun tujuan dari penelitian ini adalah menjelaskan pengaruh akupresur Perikardium 6 terhadap penurunan frekuensi mual muntah kehamilan <16 minggu Kriteria inklusi yang digunakan diantaranya: ibu morning sickness, kunjungan pertama kali, umur kehamilan <16 minggu, kehamilan normal dari pemeriksaan bidan bersedia menjadi responden. Penelitian yang digunakan adalah komparatif dengan menggunakan desain randomize prepost test control group design, yang mana kelompok intervensi diberi perlakuan berupa akupresur pada acupoint perikardium 6 sedangkan kelompok kontrol dilakukan akupresur pada tiga jari diatasacupoint Perikardium 6, dilakukan selama 5 menit setiap hari dalam 4 hari. Hasil yang ditunjukan dari penelitian ini adalah sesudah 
dilakukannya perlakuan terjadi penurunan yang bermakna pada kelompok intervensi dibandingkan pada kelompok kontrol dengan durasi mual $(\mathrm{p}=0,002)$ dan episode mual muntah $(\mathrm{p}=0,015)$, sedangkan episode muntah retching tidak terjadi penurunan yang bermakna $(\mathrm{p}=0,159)$.

Menurut penelitian yang dilakukan oleh (Safajou et al., 2014), yang berjudul "The effect of lemon inhalation aromatherapy on nausea and vomiting of pregnancy: a doubleblinded, randomized, controlled clinical trial', dengan jumlah sampel 100 wanita hamil dengan kriteria wanita hamil ini memiliki mual dengan atau tanpa muntah ringan sampai sedang, kehamilan 16 minggu, kehamilan tunggal, tidak ada tandatanda aborsi mengancam, dan tidak sedang menggunakan obat antiemetik dalam 24 jam terakhir. Sampel dibagi menjadi kelompok kontrol dan intervensi. Tujuan dari penelitian adalah untuk mengetahui pengaruh aromaterapi inhalasi lemon pada mual dan muntah selama kehamilan.Responden diminta untuk menjawab kuesioner PUQE-24, yang berhubungan dengan penilaian skor mual muntah dalam 24 jam terakhir, dan jika skor mereka antara 3-12 (mual dan muntah ringan sampai sedang), mereka terdaftar dalam penelitian. Metode penilaian yang digunakan adalahKoefisien Alpha Cron- bach $(0,81)$. Diberikan pada kelompok intervensi yaitu minyak atsiri lemon dan pada kelompok kontrol akan diberikan placebo, dihirup pada saat responden mengalami mual muntah. Caranya dengan memberikan 2 tetes (10 ml) pada kapas yang sudah disediakan, kemudian mendekatkan ke hidung sekitar $3 \mathrm{~cm}$ kemudian menghirupnya dengan hidung kekitar 3 kali hirupan.Hasil dari penelitian yaitu menunjukkan adanya perbedaan yang signifikan secara statistik antara kedua kelompok dengan skor rata-rata mual dan muntah pada hari kedua $\mathrm{P}=0,017$ dan keempatdan $P=0,039$. Intensitas mual dan muntah pada hari kedua dan keempat pada kelompok intervensi secara signifikan lebih rendah daripada kelompok kontrol. Selain itu, pada perbandingan intra-grup dengan ANOVA dilakukan pengukuran berulang, mual dan muntah rata-rata dalam lima interval, menunjukkan perbedaan yang signifikan secara statistik pada masing-masing kelompok (kelompok intervensi $\mathrm{P}<0,001$ dan kelompok kontrol $\mathrm{P}=0,049$ ). Jadi dalam penelitian menyimpulkan bahwa aroma lemon bisa efektif dalam mengurangi mual dan muntah kehamilan.

Menurut penelitian yang dilakukan oleh (Santi, 2013), dengan judul "Pengaruh Aromaterapi Blended Peppermint dan Ginger Oil terhadap Rasa Mual pada Ibu Hamil Trimester Satu di Puskesmas Rengel Kabupaten Tuban" dengan jumlah sampel 41 responden dengan menggunakan teknik sampling purposive sampling. Penelitian ini menggunakan jenis penelitian pre eksperimen dengan 
desain "One Group Pre test Post test Designs". Tujuan dari penelitian adalah menganalisis pengaruh aromaterapi blended peppermint dan ginger oil terhadap rasa mual pada ibu hamil trimester I di Puskesmas Rengel Kabupaten Tuban.Adapun variabel yang digunakan yaitu variabel bebas meliputi aromaterapi blended peppermint dan ginger oil, sedangkan untuk variabel terikat adalah rasa mual ibu hamil trimester satu. Dan uji analisa data menggunakan $U j i$ Wilcoxon Sign Rank Test. Hasil dari penelitian dengan nilai $\mathrm{p}=0,0001(\mathrm{p}<$ 0,05), $\mathrm{H} 1$ diterima dan $\mathrm{H} 0$ ditolak yang artinya terdapat pengaruh aromaterapi blended peppermint dan ginger oil terhadap rasa mual pada ibu hamil trimester I di Puskesmas Rengel Kabupaten Tuban. Dari penelitian ini dapat disimpulkan, bahwa perlakuan untuk mengurangi mual muntah pada ibu hamil bisa dengan aromaterapi lain seperti aromaterapi yang dipakai dalam penelitian ini, dan terbukti. Hanya perbedaan pada pemberian tetesan aromaterapi yang dicampurkan air saja, contohnya pada penelitian yang dilakukan oleh penulis di Desa Rawalo Kabupaten Banyumas saat pemberian aromaterapi citrus itu hanya menggunakan 2 tetes yang dicampur dengan $100 \mathrm{ml}$ air, namun pada penelitian ini pencampuran dilakukan dengan 3 tetes blended peppermint dan ginger oil.

Pada penelitian yang dilakukan oleh penulis di Desa Rawalo Kabupaten Banyumas, yang dilakukan pada minggu ketiga Bulan Juli 2018. Penelitian ini bertujuan untuk mengetahui keefektifan akupresure pericardium dan aromatherapy citrus untuk mengurangi mual muntah pada ibu hamil, dengan sampel yang digunakan 3 responden. Kriteria inklusi diantaranya yaitu ibu hamil yang mengalami ketidaknyamanan mual muntah, riwayat kehamilan normal, tidak mempunyai penyakit menyerta, umur 20-35 tahun, tidak ada gangguan penciuman, dan bersedia menjadi responden. Penelitian yang digunakan adalah penelitian deskriptif dalam studi kasus dengan observasi tingkat mual muntah responden sebelum dan sesudah diberikan akupresur pericardium dan aromaterapi citrus. Kepada ketiga responden dilakukan tindakan acupressurepericardium 6 selama 3-5 menit dengan penekanan tidak terlalu kuat juga tidak terlalu ringan dan memberikan aromatherapycitrus selama kurang lebih 10-20 menit selama 4 hari berturut-turut. Hasil penelitian yang dilakukan menunjukan keefektifan penerapanacupressure pericardium dan aromatherapy citrus pada ibu hamil mual muntah acupressure pericardium titik 6 da dibarengi dengan pemberian inhalasi aromaterapi citrus jika ibu merasa mual dan muntah yang dilakukan selama 4 hari berturut-turut. 
Tabel 4.1 Tingkat mual muntah dan kategori mual muntah sebelum diberikan perlakuan

\begin{tabular}{lllll}
\hline $\begin{array}{c}\text { Nama } \\
\text { Responden }\end{array}$ & \multicolumn{2}{c}{ Tingkat mual muntah } & Skala \\
Berat & Sedang & Ringan & $\begin{array}{c}\text { mual } \\
\text { muntah }\end{array}$ \\
\hline Ny. K & - & $\checkmark$ & - & Sering \\
\hline Ny. R & - & - & $\checkmark$ & Sering \\
\hline Ny. S & - & - & $\checkmark$ & Sering \\
\hline
\end{tabular}

Dari data di atas bahwa ketiga responden mengalami mual muntah yang sering dengan tingkat mual muntah yang berbeda, 2 responden $(66,7 \%)$ mengalami tingkat mual muntah ringan dan 1 responden $(33,3 \%)$ mengalami tingkat mual muntah sedang.

Tabel 4.2 Tingkat mual muntah dan kategori mual muntah setelah diberikan perlakuan

\begin{tabular}{|c|c|c|c|c|}
\hline \multirow{2}{*}{$\begin{array}{c}\text { Nama } \\
\text { Responden }\end{array}$} & \multicolumn{3}{|c|}{ Tingkat Mual Muntah } & \multirow{2}{*}{$\begin{array}{c}\text { Skala } \\
\text { mual } \\
\text { muntah }\end{array}$} \\
\hline & Berat & Sedang & Ringan & \\
\hline Ny. K & - & - & $\checkmark$ & $\begin{array}{l}\text { Kadang- } \\
\text { kadang }\end{array}$ \\
\hline Ny. R & - & - & - & Tidak \\
\hline Ny. S & - & - & - & Tidak \\
\hline
\end{tabular}

Dari tabel di atas dapat diinterpretasikan bahwa ketiga responden sama-sama mengalami pengurangan tingkat mual muntah setelah dilakukan perlakuan secara statistik. Pada hari pertama kunjungan rumah ketiga responden masih mengalami mual muntah sering, pengurangan mual muntah terjadi pada saat peneliti melakukan kunjungan rumah hari kedua dan ketiga. Hasil pada artikel yang telah direview, mengatakan bahwa akupresur perikardium dan pemberian aromaterapi jeruk mempunyai pengaruh terhadap penurunan mual muntah pada ibu hamil Trimester I.

Pencegahan dan perawatan pada ketidaknyamanan mual muntah dilakukan bisa dengancara duduk bersender atau dengan berbaring. Pada saat posisi ternyaman responden diberikan teknik akupresur perikardium 6 selama kurang lebih 3-5 menit. Terapi akupressur perikardium, dilakukan dengan cara menekan secara manual pada titik 6 di daerah pergelangan tangan yaitu 3 jari dari daerah distal pergelangan tangan antara dua tendon. Terapi akupresur yang digunakan inidapat menstimulasi sistem regulasi juga dapat mengaktifkan mekanisme neurologi dan endokrin yang merupakan mekanisme fisiologi dalam mempertahankan. Adapun pada artikel yang telah direview, kepada kelompok perlakuan diberikan gelang Sea Band elastis dengan kancing yangmenekan pada titik P6 dipakai terus menerus kecuali ketika ibu mandi, intervensi dilakukan selama 7 hari.

Pada saat dilakukannya akupresurpericardium jugadiberikan inhalasi aromaterapi citrus untuk rileksasi yang sudah ada di dalam diffuser (campuran $100 \mathrm{ml}$ air dan 2 tetes aromaterapi citrus) selama 10-15 menit pada saat itu juga.Literature review yang telah di telaah juga mengatakan ada banyak jenis minyak essensial yang ada. Namun, jenis minyak essensial yang biasa digunakan untuk mengatasi mual muntah seperti 
peppermint,

lemon/citrus,dan jahe.

Dengan dilakukannya perlakuan

akupresur perikardium dan pemberian inhalasi aromaterapi citrus pada saat kunjungan secara statistik, pun responden bisa melakukan secara mandiri saat merasakan mual muntah efektif dalam mengurangi rasa mual muntah tersebut. Penelitian ini menunjukkan keefektifan penerapan acupressure pericardium selama 3-5 menit dan dengan dibarengi pemberian aromatherapy citrus selama 10-15 menit yang dilakukan selama 4 hari beruturut terhadap ketiga responden, perlakuan ini membuktikan keberhasilan mengurangi mual muntah pada ibu hamil.

\section{Simpulan}

Berdasarkan dari beberapa literature rivew yang telah dianalisa oleh penulis, dapat disiumpulkan bahwa penggunaan metode acupressure pericardium dan aromatherapy pada ibu hamil dalam mengurangi mual muntah menunjukkan keefektifannya. Aromaterapi yang dapat digunakan juga tidak hanya satu macam. Contohnya dengan aromaterapi citrus, lavender, ginger, lemon, peppermint, dan masih banyak lagi.

Pemijatan pericardium titik 6 (P6) ini dapat dilakukan selama 3-5 menit dengan penekanan yang tidak terlalu kuat dan tidak terlalu ringan, dan dibarengi pemberian inhalasi aromaterapi citrus selama 10-15 menit juka ibu merasakan mual dan muntah.

Saran untuk pelaksanaan literature review selanjutnya dapat diantaranya :

a. Database yang digunakan lebih bervariasi agar lebih banyak lagi artikal yang didapatkan.

b. Batasan tahun pencarian artikel sebaiknya 5 tahun terakhir agar artikel yang ditelaah lebih terkini

c. Keyword untuk mencari artikel lebih rinci agar literature review selanjutnya lebih fokus.

\section{Daftar Pustaka}

Agustina, C., Hadi, H. \& Widyawati, M. N. 2016. Aromatherapy Massage as an Alternative in Reducing Cortisol Level and Enhancing Breastmilk Production on Primiparous Postpartum Women in Semarang. ASEAN/Asian Academic Society International Conference Proceeding Series.

Damarasri, N. D. 2017. Penerapan Pemberian Aromaterapi Lemon dan Minuman Jahe untuk Mmengurangi Emesis Gravidarum pada Ibu Hamil Trimester I di BPM Sri Jumiyati Kabupaten Kebumen. STIKES Muhammadiyah Gombong.

Danise, T. 2009. Mual dan Muntah Kehamilan dalam Nausea and Vomiting in Pregnancy: An Integrated Approach to Care. Alih bahasa Devi Yulianti. Jakarta: EGC. 
Ebrahimi, N., Maltepe, C. \& Einarson, A. 2010. Optimal management of nausea and vomiting of pregnancy. International journal of women's health, 2, 241.

Ermalena, D. 2017. Indikator Kesehatan SDGs di Indonesia.

Fengge, A. 2012. Terapi akupresur manfaat dan teknik pengobatan. Yogyakarta: Crop Circle Corp.

Fitriana, D. 2017. Perbandingan efektifitas akupresure perikardium dengan aromaterapi terhadap penurunan mual muntah pada Ibu hamil di Pulau Lombok. Prim A: Jurnal Ilmiah Ilmu Kesehatan, 2.

Jimbo, D., Kimura, Y., Taniguchi, M., Inoue, M. \& Urakami, K. 2009. Effect of aromatherapy on patients with Alzheimer's disease. Psychogeriatrics Journal, 9, 173-179.

Kemenkes. 2017. Pemenuhan SDM Kesehatan dalam Mendukung PIS-PIK dan Germas. Kalimantan Selatan; Badan Pengembangan Dan Pemberdayaan SDM Kesehatan- Kemenkes RI.

Madjunkova, S., Maltepe, C., Koren, G. J. O. \& International, G. 2013. The leading concerns of American women with nausea and vomiting of pregnancy calling Motherisk NVP Helpline. Obstetrics gynecology international Journal.
Mc Carthy, F. P., Khashan, A. S., North, R. A., Moss-Morris, R., Baker, P. N., Dekker, G., Poston, L., Kenny, L. C. \& Consortium, S. 2011. A prospective cohort study investigating associations between hyperemesis gravidarum and cognitive, behavioural and emotional well-being in pregnancy. PloS one Journal, 6, e27678.

Nur, D., Suharyo, H. \& Triana, S. H. 2014. Pengaruh Akupresur Perikardium 6 Terhadap Mual Muntah Kehamilan Kurang 16 Minggu. Jurnal Kesehatan Ibu dan Anak 5, 88-95.

Prawirohardjo. 2010. Ilmu Kebidanan. Jakarta: YBP-SP.

Runiari, N. 2010. Asuhan keperawatan pada klien dengan hiperemesis gravidarum : penerapan konsep dan teori keperawatan. Jakarta: Salemba Medik.

Saberi, F., Sadat, Z., AbedzadehKalahroudi, M. \& Taebi, M. 2013. Acupressure and ginger to relieve nausea and vomiting in pregnancy: a randomized study. Iranian red crescent medical journal 15, 854.

Safajou, F., Shahnazi, M. \& Nazemiyeh, H. J. I. R. C. M. J. 2014. The effect of lemon inhalation aromatherapy on nausea and vomiting of pregnancy: a double-blinded, randomized, controlled clinical trial. Iranian Red Crescent Medical Journal 16. 
Santi, D. R. 2013. Pengaruh Aromaterapi Blended Peppermint dan Ginger Oil terhadap Rasa Mual pada Ibu Hamil Trimester Satu di Puskesmas Rengel Kabupaten
Tuban. Jurnal Sain Med, 5, 5255.

Tillett, J. \& Ames, D. 2010. The uses of aromatherapy in women's health. The Journal of perinatal neonatal nursing, 24, 238-245. 